\title{
Benefits and Challenges of International Financial Reporting Standard (IFRS) Transition in Ethiopia (Case Study on Some Selected Organizations in Ethiopia)
}

\author{
Netsanet Shiferaw Demissew Assefa \\ Department of Accounting and Finance, Dire Dawa University
}

\begin{abstract}
The purpose of this study is to assess the transition of International Financial Reporting Standards (IFRS) in Ethiopia: the benefits, prospects and challenges of its adoption and implementation in the case of 13 significant PIEs. The study employs both quantitative and qualitative methods (mixed) research approach. Both primary and secondary data sources were used for the study. The respondents are selected by using judgmental sampling technique. Then, the collected data from those organizations is analyzed by descriptive and econometric analysis by using SPSS software. The results revealed that the adoption of the IFRSs has improves the efficiency and effectiveness of financial reporting, provides better information for decision making, enhanced the accuracy; reliability and comparability of accounting information, simplify the process of Merger/Acquisition , enables greater effectiveness of the internal audit, brings better corporate governance, reduce cost of capital, better access to capital market, harmonize the reporting standard, better risk management, promotes cross border investments and provide timely financial report. However, there is serious educational, technical and institutional challenges that the country need to overcome in order to benefit fully from the adoption of IFRS.
\end{abstract}

Index Terms- International Financial Reporting Standards, Benefits, prospect, Challenge, implementing.

DOI: $10.7176 /$ RHSS/10-11-03

Publication date:June 30th 2020

\section{INTRODUCTION}

\subsection{Background of the study}

As of the beginning of 2005, by having variation in accounting practices and financial information asymmetry, the global corporate financial reporting landscape has been transformed. As result, a single global accounting standard all over the world established. International financial reporting standards (here after IFRS) is designed as a common global language for business affairs. Adoption of IFRS is more than accounting exercise. Conversion to IFRS does not end with the publication of the first set of IFRS compliant financial statements. IFRS refers to a series of accounting pronouncements published by the International Accounting Standards Board in order to produce reliable and relevance information throughout the world, produce and present high quality, transparent and comparable financial information. (AABE, 2015)

According to Demaki (2013), Diversity in financial reporting in different countries arises due to the differences in culture, legal systems, tax systems and business structures. The IFRS is intended to harmonies these diversity by providing comparable and transparent financial information and thereby reduce cost of capital. According to Sedzani and Minor (2012), geographical boundaries become less significant, since most countries want to adopt common language around the world. The international reporting practice has improved in line with globalization; consequently the national accounting system is no longer accepted by the most of international organization. IFRS is designed as a common global language for business affairs so that company accounts are understandable and comparable across international boundaries. In related with this the need of IFRS is particularly important for companies that have dealings in several countries since it progressively replacing national accounting principles by internationally accepted standards. According to Ginaet.al (2016), the information provided by the company for the user required to be prepared in line with universally accepted assumptions, principles and conventions of accounting which aid intra-firm, inter-firm and industry comparisons overtime. To get advantage and to encourage foreign direct investment, currently there are more than 166 jurisdictions in the world adopt or converged to IFRS. (IFRS Foundation, 2017)

\subsection{Statement of the problem}

According to IFRS Foundation (2017), today world's financial markets are borderless. Investor and lender seek investment opportunities with high return and less risk whenever it is available. To assess the risks and returns of their various investment opportunities, investors and lenders need financial information that is relevant, reliable and comparable across borders. The adoption of IFRS is often justified by the expected economic benefits for preparers of financial statements.

Thus, the use of one set of high-quality standards by companies throughout the world improves the comparability and transparency of financial information and allocate funds more efficiently in turn firms can 
achieve a lower cost of capital and this Promote cross border investment and reduces cost. Particularly, the adoption of IFRS by the developing countries is not only imperative but also required in order to access the capital markets at the global level. (Mohamed, 2014)

According to Edeigba et.al (2018), one of the main reasons for developing countries such as Nigeria, Ghana, Indonesia, and Fiji to implement IFRS is the "network effects". The network effect is the international trade relationship between companies from different countries using a similar accounting approach for recognition, measurement, and disclosure. According to Teferi et.al (2016), using different national accounting standards are used in different countries which make difficult and costly to compare investment opportunities and alternatives in different countries. In spite of this fact in many developing countries the quality of local governance institutions is low and thus this make the adoption of IFRS attractive to them. Adopting IFRS has not an easy task for the countries because as it makes necessary reforms to a country's regulatory, legal and economic structures and adaption of its culture to the West. Oghogho et al. (2016), even though there is no doubt that conversion to IFRS in developing countries are a huge task and a big challenge; however the adoption and implementation of IFRS should be on the basis of cost- benefit analysis. Therefore, before adopting IFRS those countries should consider different factor that affects the adoption process particularly in the case of developing countries. Since EU was the first to adopt IFRS across the globe, most of the research has been carried out on IFRS based on the data from member countries from EU.As cited by Mohamed (2014), Kholeif (2008) and Braun (2014) suggested that there is a needs to made further studies about IFRS in emerging countries and examine the challenges that facing during implementation process in developing nations. Samaha and Khlif (2016) stated that, compared to developed countries, IFRS research remain under-researched in developing countries including Ethiopia.

\subsection{Purpose statement}

The study tried to answer the following specific research questions;

$>$ What are the benefits or prospects of adopting and implementing IFRS in Ethiopia?

$>$ What are the underlying factors that initiate the adoption of IFRS?

$>$ What are the problems faced by companies in the process of adopting and implementing IFRS?

\subsection{Objectives of the Study}

\subsubsection{General Objective of the study}

The General Objective of the study is to assess the Benefits and Challenges of IFRS transition in Ethiopia in the case of 15 significant PIEs in Ethiopia.

\subsubsection{Specific objectives of the study}

$>$ To assess the benefits of adopting and implementing of IFRS in Ethiopia.

$>$ To explore the factors that initiate for the adoption of IFRS in Ethiopia.

$>$ To identify the challenges of adopting and implementing IFRS in Ethiopia.

\section{LITERATURE REVIEW}

\subsection{International Financial Reporting Standards}

The IFRS is designed as a common global language for business affairs so that company accounts are understandable and comparable across international boundaries. They are a consequence of growing international shareholding and trade. The IFRS is particularly important for companies that have dealings in several countries. They are progressively replacing the many different national accounting standards. www.IFRS.org

The IFRS began as an attempt to harmonize accounting across the European Union, but the value of harmonization quickly made the concept attractive around the world. They are occasionally called by the original name of International Accounting Standards (IAS). The IAS was issued between 1973 and 2001 by the Board of the International Accounting Standards Committee (IASC). On April 1, 2001, the new IASB took over the responsibility for setting International Accounting Standards from the IASC. During its first meeting the new Board adopted existing IAS and Standing Interpretations Committee standards (SICs). The IASB has continued to develop standards calling the new standards the IFRS.

The main aims of IFRS Standards are bring Transparency, Accountability and Efficiency to financial report around the world. IFRS Standards bring transparency by enhancing the international Comparability and quality of financial information, enabling investors and other market participants to make informed economic decisions. While IFRS Standards strengthen accountability by reducing the information Asymmetry between the providers of capital and the people to whom they have entrusted their money. Again IFRS Standards contribute to economic efficiency by helping investors to identify opportunities and risks across the world, thus improving capital allocation. (IFRS Report, 2017)

\subsection{Benefits and Prospects of Adopting IFRS}

Gina etal (2016) discloses some advantages of adoption of IFRS in developing and less developed countries. 
Among the benefits, Attraction of investment and financial support, Bridge Communication gap with Stakeholders by increasing the level of confidence of global investors and investment analysts, Attraction of More Foreign Direct Investments (FDIs) related with more reliable and credible financial statements, Uniformity in Accounting Language by eliminating the unnecessary complexity that exists with multiple reporting languages and the lower susceptibility to political pressures than national standards. In line with these benefits, those countries want to adopt IFRS should emphasis on the following areas; strengthen professional education and training, Strengthen capacity of the regulatory body,create awareness to reduce the knowledge gap, provide an adequate resource, and establish an autonomous body to set monitor and enforce accounting and auditing standards and codes.

The study made by Teferi et.al (2016) focuses on adoption of IFRS progress in Ethiopia; investigate factors that motivate Ethiopia to adopt IFRS and to identify benefits and challenges ahead of adopting IFRS. The study reveal that reduction of agency problem, accounting diversity and cost of investors for processing financial information, improving financial reporting quality the benefits that the company acquire by adopting IFRS. There are also opportunities stated in the study in the process of adopting IFRS. These are High commitment from the Government, Enhance Comparability of financial Statement, Enhance FDI, Easy Access to Finance, Helps to establish legal backing accounting and auditing system.

Melese (2016), found that Adoption of IFRS provide numerous benefits for Ethiopian financial institutions including to improved comparability \& reliability of financial statements, reduce cost of capital of firms through lower cost of information, minimize information asymmetry between stakeholder, greater marketability of shares, and reduced information asymmetry and increase investors' confidence on financial reports and enhances transparency of companies' reports for investors.

\subsection{Challenges of Adopting IFRS}

Edeigba et.al (2018) stated that, the challenges in IFRS adoption vary across previous studies that have attempted to identify the issues in adopting IFRS. Most of the studies examining these challenges identified legal systems, companies' characteristics such as listing status, companies' size, ownership structure and enforcement mechanism as the factors inhibiting IFRS adoption.

According to Uwadiae (2013) as cited by Edeigba et.al (2018) One of the challenges in Nigerian company in the adoption process is the dissimilarities of market data for measurement and valuation and its impacts on the comparability of financial statements (International Financial Reporting Standards Foundation, 2012). The need for availability of market data is particularly true in the case of IFRS 13 (Fair Value Accounting Standard). Another concern about the companies' adoption of IFRS is the absence of an active capital market for the measurement and valuation of some assets such as biological assets in the case of Nigerian companies.

According to Teferi et.al (2016), the challenges of adopting IFRS include Knowledge Gap, troubles relating to unexpected additional costs, lack of accounting professionals, Absence of Professional Institutions, Emergence of Unfair Competition among Professionals and unwelcoming public sentiment. Therefore, the finding of the study indicated that without making all necessary preparedness, some companies in Ethiopia have started using IFRS voluntarily for the preparation of their financial statements since 2002/03. They also suggest that the concept of IFRS should be integrated into Ethiopian higher institution curricula and also the country should develop having stock exchange market.

Similarly the result of the study made by Melese (2016), shows that the challenges of institutions for implementing IFRS are high implementation costs, the complexity of financial reporting, lack of IFRS implementation agent, lack of IFRS implementation guidance, lack of availability of competent specialists, high level training requirement, less familiarity with the IT and lack of proper instructions from regulatory bodies.

Furthermore, Firdawok (2017) made a study to identify the challenges and prospects of International Financial Reporting Standard (IFRS) implementation in Ethiopia. The study found that some of the key challenges facing for the transition to IFRS are significant cost of adoption, need for training, lack of readiness to implement within the timeframe set by the board, lack of adequate implementation guidance and lack of enforcement capacity. The result of the study reviled that Institutional readiness; Enforcement mechanism/capacity and availability of the required expert capacity have significant effect on the transition to IFRS in Ethiopia. Finally, for a smooth adoption of IFRS, Independent Auditors and Accountants and Regulators and Law Makers will have to come together and work as a team and there should be proper training and awareness creation is important.

\subsection{Theoretical Framework}

The major objective of the study is to assess the Benefits and Challenges of Harmonized international financial accounting standards in to the practice of the local accounting standard in the case of 13 significant PIEs in Ethiopia. By having this objective, the theoretical frame work is formed as follow; 


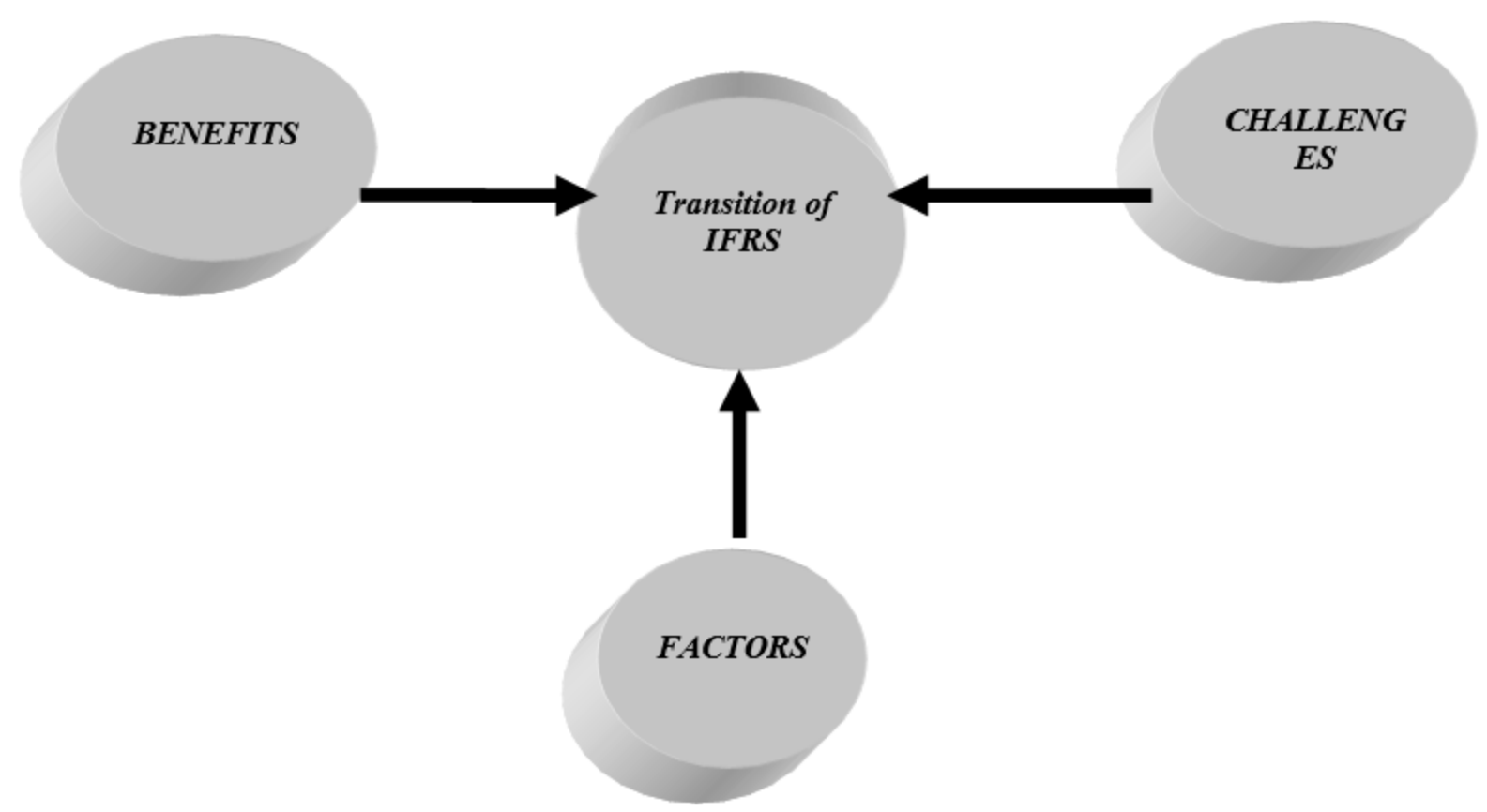

Source; - Joseph (2018) page. 104 (with modification)

Figure1. Theoretical Framework

\section{RESEARCH METHODOLOGY}

The study employs both quantitative and qualitative methods (mixed) research approach. The researchers used both primary and secondary data sources. The Primary data is collected by using a pre - designed questionnaires and unstructured interview. The main instrument for collection of data for this study is questionnaire. The questionnaires is carefully prepared based on the literature and standardize format by using both Likert and ordinal measurement scales. The questionnaires are distributed to finance officers, accountants and concerned officials of selected companies and regulatory body, i.e., AABE. Besides, the researchers used semi-structure interview to deal deeply and flexibly with the interviewee. The interview is made with the concerned officials from AABE. Secondary data was collected from the draft and final financial reports.

\subsection{Total Population}

According to the executive summary report from AABE as of January 2018 the total numbers of companies in Ethiopia that are expected to adopt IFRS and provide their first financial reports according to IFRS on July 7/2018 as Significant PIEs include Financial Institutions and public enterprises owned by Federal or Regional Governments are 64. As result, the researchers used non-random sampling technique that uses judgmental /purposive/ sampling. The reason for selecting this purposive sampling is that all expected companies are not complete the implementation process at the expected time and the selected samples help the researcher to understand the research problem and the research question deeply. Furthermore, The Company's was an early adopter of IFRS in Ethiopia and they actually realized the benefits and easily detect the challenges of implementation process. Consequently, the researchers select all significant PIEs which have high probability to make the conversion process by completing the necessary steps as stated by AABE.

\subsection{Target Population and Sample Design Technique}

Considering the target population of the study, the researchers used non-random sampling technique that uses judgmental /purposive/ sampling. The reason for selecting this purposive sampling is that all expected companies are not complete the implementation process at the expected time and the selected samples help the researcher to understand the research problem and the research question deeply. Furthermore, The Company's was an early adopter of IFRS in Ethiopia and they actually realized the benefits and easily detect the challenges of implementation process. Consequently, the researchers select all significant PIEs which have high probability to make the conversion process by completing the necessary steps as stated by AABE. The target population is from the accounting professionals of National Alcohol and Liquor Factory, Berhanena Selam Printing Enterprise, East African Bottling Share Company, Metals and Engineering Corporation, Ethiopian Petroleum Supply Enterprise, Ethiopian Airlines, Industrial Parks Development Corporation and Ethiopian Railway Corporation as significant PIEs. While among financial institutions the researchers select Commercial Bank of Ethiopia and Development 
Bank of Ethiopia from governmental financial Institutions as the banks early complete the conversion process whereas Awash Bank, since the bank are pioneer private financial institution and also Ethiopian Reinsurance from insurance companies, and National Bank of Ethiopia from regulatory body.

Considering the target population of the study, the respondent was selected by using judgmental sampling technique. The sampling units are finance department employees in various functions which include accountants, auditors, finance officer and managers in the headquarters of the respective companies and concerned body from AABE. This is due to their expertise, relevance knowledge to IFRS and local reporting practices since they are preparers and auditors of the financial statements and regulators. Therefore, the target population for the study comprised mainly practitioners from the selected companies and AABE.

The participants are drawn from stakeholders who participated directly in the IFRS adoption process in Ethiopia. Since the conversion team is the primary responsible body for the implementation of IFRS all team members are included in the study. Therefore, the researchers select 11 members from each of 13 organizations stated in the target population including accountants, auditors, finance officers and managers in the headquarters of the respective companies and from AABE. Thus, the total sample size of the study is 143 members i.e. $11 * 13$.

Purposive sampling technique also applied to select interviewees from AABE. The base to select the interviewees is the participants' deep knowledge and involvement in the IFRS adoption project. The interview is made with the key persons involved in IFRS adoption process as supervision team from AABE. According to data from AABE the supervision team consists six different groups that supervise different organizations. Thus the researchers select team leaders from each of the six groups, the financial reporting supervision directorate director and AABE general manager i.e.8 persons in total interviewed in the study.

\subsection{Methods of Data Analysis}

The study utilizes descriptive analysis by using SPSS version 20 software. The data collected from different sources is coded, checked and entered to excel program. Then the collected data was processed and analyzed by using SPSS software.

\section{DATA PRESENTATION, INTERPERETAION AND ANALYSIS}

To make the analysis a total of 145 questionnaires were distributed to significant public interest entity and financial institution in Addis Ababa which largely includes IFRS Team, Finance Manager, Accountant and Auditor of 13 selected entities depending on the number of participants engaged in the IFRS conversion process. Therefore, out of the total 145 questionnaires, 132 were filled and returned back to the researchers where as 13 questionnaires where unreturned. Which means the overall response rate of the study was $91 \%$. Compared to other IFRS adoption studies and considering the difficulty of collecting data in developing countries such as Ethiopia, 91\% response rate was good.

Background Information of Respondents

Table 4. 1. Background information of the respondents

\begin{tabular}{|c|c|c|c|c|c|c|}
\hline & \multirow[t]{2}{*}{ Variable } & \multirow[t]{2}{*}{ Frequency } & \multirow[t]{2}{*}{ Percent } & \multicolumn{3}{|c|}{ Knowledge Evaluation } \\
\hline & & & & Mean & $\begin{array}{l}\text { p- } \\
\text { value }\end{array}$ & sig \\
\hline \multirow[t]{3}{*}{ Gender } & Male & 97 & 73.5 & 3.3402 & \multirow[t]{3}{*}{.396} & \multirow[t]{3}{*}{.756} \\
\hline & Female & 35 & 26.5 & 3.3143 & & \\
\hline & Total & 132 & 100 & & & \\
\hline \multirow[t]{4}{*}{ Qualification } & Diploma & 0 & 0 & & \multirow[t]{4}{*}{.031} & \multirow[t]{4}{*}{0.9925} \\
\hline & Bachelor Degree & 88 & 66.7 & 3.3409 & & \\
\hline & Master Degree /ACCA & 44 & 33.3 & 3.3182 & & \\
\hline & Total & 132 & 100 & & & \\
\hline \multirow[t]{10}{*}{ Organization } & Commercial Bank of Ethiopia & 12 & 9.1 & & \multirow[t]{10}{*}{6.643} & \multirow[t]{10}{*}{0.00033} \\
\hline & National Alcohol and Liquor Factory & 10 & 7.6 & 3.9000 & & \\
\hline & Berhanena Selam Printing Enterprise & 6 & 4.5 & 4.3333 & & \\
\hline & $\begin{array}{l}\text { East African Bottling Share } \\
\text { Company }\end{array}$ & 12 & 9.1 & 3.5833 & & \\
\hline & Metals and Engineering Corporation & 17 & 12.9 & 3.4706 & & \\
\hline & $\begin{array}{lll}\text { Ethiopian } & \text { Petroleum } & \text { Supply } \\
\text { Enterprise } & & \\
\end{array}$ & 12 & 9.1 & 4.0000 & & \\
\hline & Ethiopian Airlines & 10 & 7.6 & 3.7000 & & \\
\hline & Industrial Parks Develop Corporation & 5 & 3.8 & 3.4000 & & \\
\hline & Ethiopian Railway Corporation & 9 & 6.8 & 3.0000 & & \\
\hline & Awash Bank & 12 & 9.1 & 2.5833 & & \\
\hline
\end{tabular}




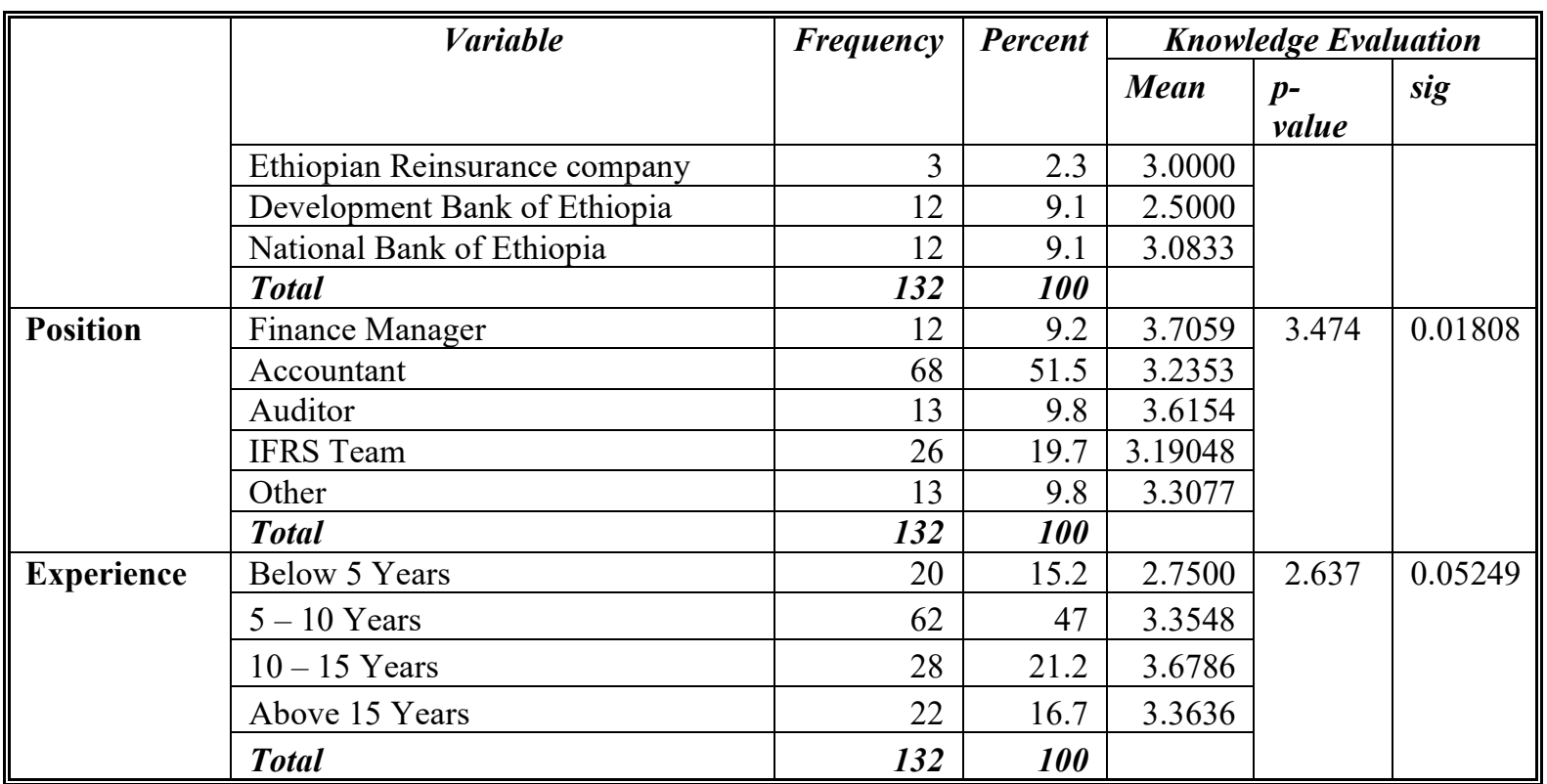

Source; Questionnaires 2019

Previous studies Dauda et.al (2015) have evidenced that IFRS knowledge is important factor in the adoption and the influence of knowledge on transition process has been proven in various researches, this part also associate demographic variables with knowledge. To analyze the background information of participant's Descriptive statistics, T-test and one-way ANOVA was used. As it is shown in the above table, by considering the sex composition and level of Qualification, majority of respondents are male and since almost all of the respondents are educated, it can be concluded that all groups are capable of understanding and answering the questions. In addition by having the result of T-test and one-way ANOVA gender and level of qualifications are insignificant factor to determine the level of knowledge.

As indicated in the above table, the information gathered for this study was collected from various concerned bodies participated in the conversion process. For this reason, the researchers believed that the information obtained from appropriate respondents and the respondents has average knowledge on the transition process. the result of cross tabulation indicates that there is difference in knowledge across organization and it is significant factor. Beside all respondent have moderate knowledge based on the experience level and experience is significant factor to determine the level of knowledge.

\subsection{Knowledge Evaluation}

The findings show that the level of awareness about Pros/Cons of applying IFRS have the mean value of 4.5455 and standard deviation of 1.01413 which indicate that the respondent have a good understanding about the Pros/Cons of applying IFRS. In addition the mean value and standard deviation for redness of auditors, accountants and accounting students for the conversion process is 3.15909 and of 0.903980 respectively. Therefore these indicate that on average accounting professional have readiness for the convergence to IFRS.

\section{2. "Major Reasons" for being positive in applying IFRS}

KMO and Bartlett's Test

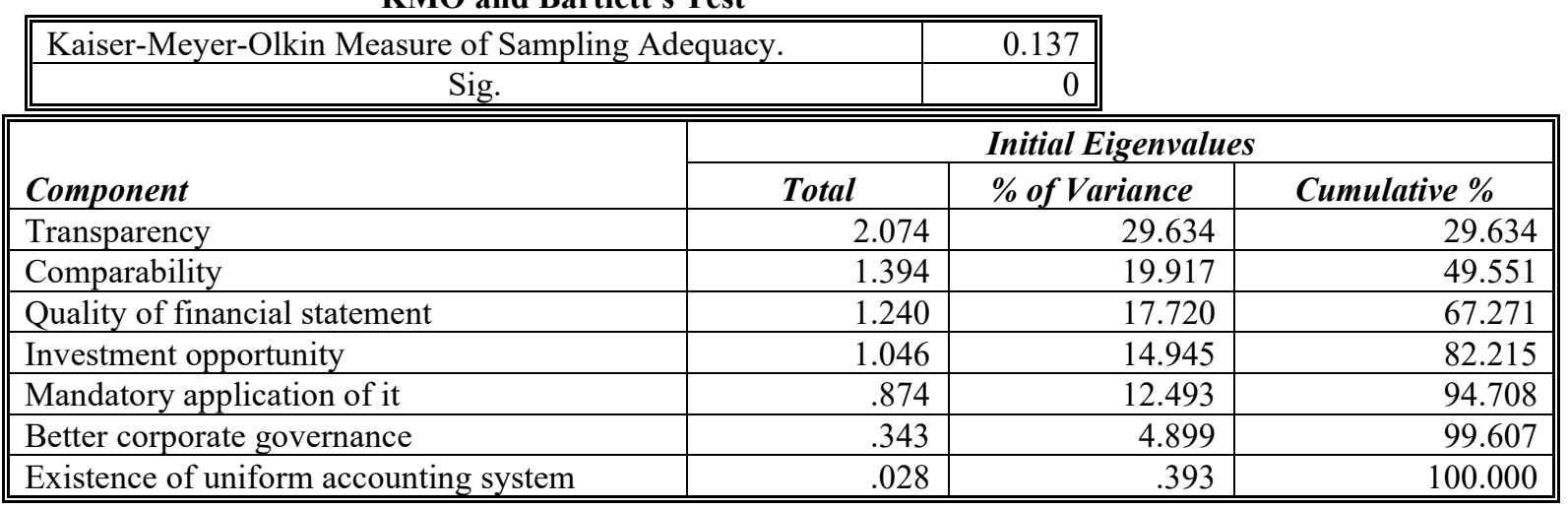

Source; Questionnaires 2019

Principal component analysis (varimax) was applied to test their construct validity. From the result of the above 
table, the researchers have used only variables with factor which have eigenvalue of 1.0 and more to build up the positive factors for the adoption of IFRS. Consequently the respondents at large as well as the interview result revealed that the adoption of IFRS provides high level of transparency because IFRS demands higher disclosure levels, quality measurement and recognition rules. Also it is believed that, the adoption of IFRS will lead to comparability of financial statements, enhancing the quality of financial statements and creating investment opportunity at large for the company.

\section{3. "Major Reasons" for being negative in applying IFRS} KMO and Bartlett's Test

\begin{tabular}{|c|r||}
\hline Kaiser-Meyer-Olkin Measure of Sampling Adequacy. & .148 \\
\hline Sig. & .000 \\
\hline \hline
\end{tabular}

\begin{tabular}{||l|r|r|r||}
\hline \multirow{2}{*}{ Component } & \multicolumn{3}{|c||}{ Initial Eigenvalues } \\
\cline { 2 - 4 } & \multicolumn{1}{|c|}{ Total } & \% of Variance & \multicolumn{1}{c|}{ Cumulative \% } \\
\hline High cost of adoption & 2.383 & 47.651 & 47.651 \\
\hline Lack of knowledge & 1.341 & 26.821 & 74.472 \\
\hline Human psychology (resistance to adopt new things) & .698 & 13.961 & 88.433 \\
\hline Lack of training & .573 & 11.465 & 99.898 \\
\hline Broad changes in accounting world & .005 & .102 & 100.000 \\
\hline
\end{tabular}

Source; Questionnaires 2019

Similarly with the above analysis, the researchers have used only variables with factor which have eigenvalue of 1.0 and more to build up the negative factors for the adoption of IFRS. Based on the result the respondents at large agreed that lack of knowledge and lack of training are the major negative reason that makes difficult the implementation process of IFRS since the standard need new knowledge to make the report. In related with this High cost of adoption and Human psychology (resistance to adopt new things) due to the new standard will require them to exert additional effort and changing the standard they already mastered to the new that they do not know is also another reason for being difficult the adoption process. In addition, the interview result reviled that Institutional readiness, availability of the required skill in the market, difficulties in the application and enforcement issues are the major hindrance for the implementation of IFRS.

\subsection{Benefits of Adoption IFRS to Companies}

The discussion about the benefits is made by classifying those benefits as benefits to companies and benefits to investors. For this study the researchers used 5 point Likert scale and indicate the extent they agree with the statements that: $1=$ Strongly agree, 2 = agree, $3=$ Undecided, $4=$ disagree $5=$ Strongly disagree. A mean (M) score between 0.8 and 1.6 means that there respondents strongly agreed, between 1.6 to 2.4 means they agreed, between 2.4 to 3.2 means the respondents were neutral or undecided, between 3.2 and 4 means they disagreed, and a mean of greater than 4 means the respondents strongly disagreed.

The first analysis is made in related with the benefits of IFRS in preparation of financial statements. In this regards as many respondents (with mean response between 1 and 2) believe that adoption of IFRS will simplify financial statement, provide more reliable, comparable and harmonized financial statement. The findings of this survey seem consistent with the results of the survey carried out by Owolabi \& Iyoha (2012). Similarly, the interview result reveals that since IFRS harmonized financial statement by creating a single accounting language, adoption of IFRS leads to improved comparability and reliability of financial statements. The mean value for the question that Merger/Acquisition became easy through IFRS, IFRS make better access to capital market and Ease of using one consistent reporting standard in subsidiaries from different countries were less than 2. This indicates that in the view of respondents, the adoption of IFRS make easy of merger, better access to capital market and create constant standard in the national as well as international level. Similarly the result of the study indicates that IFRS improves the Accuracy \& reliability of reported earnings and financial position, it brings better corporate governance, reduce cost of capital and make internal audit easier and less costly. The interview result also indicate that the adoption of IFRS increased transparency substantially it make internal audit easier and less costly through lower cost of information.

The mean response for the question about the benefits of adopting IFRS for company was below 2 and standard deviation of less than one. This shows that in the view of respondents the adoption of IFRS will provide; better information for decision making, confident information, Better understanding of risk and return, comparable financial statement, timely financial report and save time. The results of this study are supported by the conclusion forwarded by Michael (2013) and Eyob (2017).

\subsection{Key success factors for IFRS adoption}

Under Key success factors for adoption of IFRS, the mean values for all questions were almost between 1 and 2 , 
standard deviation around one and less than one. This revels that the respondents had a positive response and close to one another. The respondents at large agreed that the Implementation of IFRS will reduce information asymmetry. From the interview result, this is due to as financial statements are more transparent and reflects the economic position, information asymmetries between firms and their shareholder is also reduced. Respondents have also agreed that the role of Board and executives support to convergence with IFRS to successfully adopt and implement IFRS is crucial. On other hand, the adoption IFRS eliminates multiple reporting accounting languages, as result the accounting professionals can be employed everywhere in the world.

The study also indicates that smooth functioning of IFRS to a large extent depends upon university curriculum and coordination with professionals is important for the successful adoption of IFRS. In addition, the external environment forces such as IMF, WORLD BANK influenced IFRS adoption in Ethiopia. The interview result also reveals that one of the most important factors that promot the adoption of IFRS is absence of national accounting standard in Ethiopia. Furthermore, the existence of capital market has led governments to adopt IFRS, in the expectation that adoption of IFRS provide comparable and transparent financial statement for local and international investors. The results of this study is consistent with the conclusion forwarded by Eyob (2017)

In general the current environment for having single high quality accounting standards both inside and outside, good financial reporting framework established the culture of each country impact on accounting and IFRS Harmonization

\subsection{Challenges of IFRS adoption}

Even though the benefits are longer lasting than the problems in applying IFRS, the companies are facing many challenges in the process of adopting IFRS. With mean value of 2.58 and Standard deviations of 1.05 the respondents agree that IFRS are complex and difficult. The broader nature of the standard made it not easily understandable. By having this complexity, IFRS materials are available in foreign currencies and the materials are updated regularly and these also increase the cost of IFRS implementation. In related with this, the respondent also stated that frequent changes on IFRS are also one of the most important challenges with mean value of 2.31 and standard deviations of .89. The questionnaire as well as the interview result reviled that the adoption of IFRS need sufficient preparatory period for planning and making all necessary resources required available to handle all the changes that will result changes in system, procedures and operation. However the interview conducted with interviewees from sample companies revealed that their companies started using IFRS without passing through these necessary steps. In general, most of respondent agree that the financial resource, insufficient time, inadequate training and complex nature of the standards are the most important challenge in the transition process. This finding also supported by the results of this study made by Faraj et.al (2014), Firdawok(2017), Herbert et.al (2013)

The mean value for IFRS requires immediate change in Ethiopian tax accounting policies and practices, and Conflict between Ethiopian laws and IFRS is 2.58 and 2.66 respectively. According to the result of this study, lack of coherence between existing laws and IFRS is the main challenge for adoption of IFRS. The interview result moreover indicates that the Ethiopian laws are not updated according IFRS such as tax law. This result also consistent with many other studies i.e. Ball (2006) and Michael (2013), stressed the challenges that most countries will face in adopting and implementing IFRS is that of changing culture and developing systems of regulation and accountability.

The respondents at large strongly agree that the Accounting and Auditing professionals need to be trained for effective migration to IFRS. However, there is lack of qualified people to provide such kind of training in profession and those training which is given also focused on theoretical part not concern on the actual practical gap in the area. Moreover, Respondents agree that there is a challenge for not having adequate technical competence in applying IFRS. IFRS based financial statements will not provide a fair picture of financial position of companies in countries suffering from hyper-inflation since there is no sufficient information is available to get exact inflation rate. Absence of fair value measurement and shortage of professional are among the challenges face in transition process. One of the reasons for this shortage is most of Ethiopian Universities and colleges are not offering the Courses according to IFRS. Further the study indicates that, there is Inadequate regulatory bodies to monitor and ensure compliance with IFRS. The result of this study is consistent with previous study made by Edeigba et.al (2018), and Ehijeagbon and Beauty (2014)

On contrary, most of the respondent are disagree for the question that there is a disparity between local reporting practices and international standards (IFRS). The researchers believed that this is due to Ethiopia has no specific set of accounting standards to follow or its own national standard. Further, the interviewee indicated that there is lack of attention of management to accounting and financial reporting related issues that the management is focusing on the cost side of the project

\section{CONCLUSIONS AND RECOMMENDATION}

\subsection{Conclusion}


International financial reporting standards are vital in developing and building detailed quality financial reports that fit in the entity's operations. The results show that the introduction of IFRS in Ethiopia will result in a number of important benefits for a wide range of stakeholders. The financial information originating from developing countries is still difficult to trust, Herbert et.al (2013), despite the urgent need for countries to attract foreign investment and foreign capital. Therefore, International Financial Reporting Standard (IFRS) beneficial for developing countries because it provides them with better -prepared standards as well as the best quality of financial reports.

On top of all, first the respondents rank there expectation for positive and negative reason for the implementation of IFRS. The major positive reasons are IFRS provide transparency, comparability, enhancing the quality of financial statements and creating investment opportunity at large for the company. While lack of knowledge, lack of training, high cost of adoption, Human psychology (resistance to adopt new things), Institutional readiness, and difficulties of the application and enforcement issues are among the negative reasons.

IFRS can minimize information asymmetry between stakeholders, Board support, covering of both qualitative and quantitative aspects of accounting and harmonization are the basic factors to successfully and efficiently adopt IFRS. In addition the interview result reveals that one of the most important factors that initiate for the adoption of IFRS is absence of national accounting standard in Ethiopia and Pressure from international organizations. Furthermore, the existence of capital market has led governments to adopt IFRS.

In general, this empirical study has been conducted to assess the Benefits and Challenges of International Financial Reporting Standard (IFRS) Transition in Ethiopia. This study confirmed that, there is growing appreciation of the usefulness of IFRS by different companies and stake holders. Successful implementation of IFRS needs extensive and ongoing support from professional accountancy associations. However, there is serious educational, technical and institutional challenges that the company need to overcome in order to benefit fully from the adoption of IFRS. Despite all the challenges, most of the companies successfully adopt IFRS. The result of the survey compatible with studies made in this area previously by various researchers such as (Gyasi, 2010), Madawaki (2012), Mohamed, 2014)

\subsection{Recommendation}

$>$ Since these standards are new, complex and unfamiliar, several training must be done to gain IFRS skills and knowledge. Also the training should focus on practical application of IFRS.

$>$ In order to ensure the effective transition of IFRS, there should be strong management support and corporate governance established in the organizations. The regulatory body should make strict follow up in order to insure that the financial statements are prepared in compliance with established standards.

$>$ Universities and Colleges should work in this regard and incorporate the concept of IFRS by making revision in the accounting curriculum. To have smooth transition in the country, Human-resources-development program and mechanisms should be established at national level.

$>$ As there are lack of coherence between existing laws and IFRS, there should be immediate amendment in Ethiopian law and practices to have consistency with IFRS.

$>$ Take necessary steps to strengthen capacity of regulators, professional education and create training center.

$>$ Adequate resources should be put in place to support the sustainable implementation of IFRS. As a major shift, the converging process will not be easy and needs considerable resource and time, good planning, accounting team work, proper strategy and effective leadership.

$>$ For successful implementation of IFRS, the engagement and consultation of professional bodies play a great role. Consequently, these bodies need to be strong and conduct independent oversight. The accounting and auditing board of Ethiopia, board of directors, audit committees and senior management should closely monitor and assist the IFRS adoption procedures in each company's and take necessary action on the problems encountered.

$>$ Currently the implementation is on significant public interest entity and the implementation process is continued on Small and medium enterprise. As there are a number of Small and medium enterprise in Ethiopia, there should be enough consultative groups available to respond promptly to concern by users and to provide for their ongoing training.

\subsection{Future Research Area}

How small and medium scale enterprises adopt and comply with IFRS tailored for them could also be considered as another area for future research. Other area where future researchers can focus is on the financial impact of the adoption of IFRS compared to GAAP financial statement. Moreover, this study attempted to focus on Benefits and Challenges of International Financial Reporting Standard (IFRS) Transition in Ethiopia. Even though the research found some important benefits and challenges of implementing IFRS, the researcher advocates more studies to be conducted in the area. 


\section{REFERENCES}

Accounting and Audit Board of Ethiopia, (2015). Five years strategic plan 2015/16 - 2020/2, (AABE).

Augustine, A. (2012).A Proposed Rule - Roadmap for The Adoption of International Financial Reporting Standards (IFRS) In Nigeria,American Journal of Economics, 41-45 https://DOI: 10.5923/j.economics.20120001.10

Dauda, I. A., Ombugadu, B. A., \&Aku, S. U. (2015). Threats and Challenges to Accounting Profession: A Draw Back to the Development of Accounting Practices in Nigeria. International Journal of Academic Research in Accounting, Finance and Management Sciences, 5(4), 96-104.

Demaki, G. (2013). Prospects and Challenges of International Financial Reporting Standards to Economic Development in Nigeria, Global Journal of Management and Business Research, Vol. 13, Issue 1.

Edeigba, J., Gan, C., Amenkhienan, F. (2018). The Effects of Organisational Culture on IFRS Adoption: Evidence from Nigerian' Companies. Journal of Business \& Financial Affairs: 7:1 DOI: 10.4172/2167-0234.1000318

Ehijeagbon,A., \& Beauty, E..(2014). Adoption and implementation of International Financial Reporting Standards (IFRSs) in Nigeria: Enduring challenges and implications. International Journal of Development and Sustainability, 3 ( 11), 2090-2100.

Eyob, L. (2017), Benefit and Challenges of adopting IFRS in Case of commercial Bank of Ethiopia, Msc Research Paper, St.Mary's University, Addis Ababa, Ethiopia.

Faraj, S., and El-Firjani, E. (2014). Challenges Facing IASs/IFRS Implementation by Libyan Listed Companies. Universal Journal of Accounting and Finance ,2(3), 57-63.

Firdawok, T. (2017). Challenges and Prospects Of International Financial Reporting Standards (IFRS) Implementation in Ethiopia, Msc Research Paper, Addis Ababa University, Addis Ababa, Ethiopia.

Herbert, W., Tsegba, O., Ohanele, A., \& Anyahara, I,. (2013). Adoption of International Financial Reporting Standards (IFRS): Insights from Nigerian Academics and Practitioners, Research Journal of Finance and Accounting, Vol.4, No.6.https://www.ifrs.org/

IFRS Foundation, (2017). Pocket Guide to IFRS Standards. The Global Financial Reporting Language

Joseph, M. (2018). Perceived Benefits and Challeges of IFRS Adoption in Ghana: Views of Members of Institute of Chartered Accountants, Ghana (ICAG).International Journal of Financial Research, Vol. 9, No. 1.

Madawaki, A. (2012). Adoption of International Financial Reporting Standards in Developing Countries: The Case of Nigeria. International Journal of Business and Management, Vol. 7, No. 3, pp 152-161

Melese, H.(2016). Adoption, Challenges and Perception of International Financial Reporting Standards (IFRS) on the Quality of Financial Reporting Of Financial Institution in Addis Ababa, Msc Research Paper, Addis Ababa University, Addis Ababa, Ethiopia.

Michael, O. (2013). Application and challenges of international financial reporting standards in Nigeria. Arabian Journal of Business and Management Review, Vol. 3, No.2.

Mohamed, A. (2014).Challenges of International Financial Reporting Standards (IFRS) Adoption in Libya,International Journal of Accounting and Financial Reporting,ISSN 2162-3082, Vol. 4, No. 2http://dx.doi.org/10.5296/ ijafr.v4i2.6302

Oghogho, G., IgbinosaAdeghe ,.andOmimi- EjoorO. (2016).Challenges Of the Implementation of IFRS In Less Developed And Developing Countries, Igbinedion University Journal Of Accounting | Vol. 1.

Owolabi, A,. \& Iyoha, F,. (2012). Adopting International Financial Reporting Standards (IFRS) in Africa: benefits, prospects and challenges. African J. Accounting, Auditing and Finance, Vol. 1, No. 1.

Pricope, C. F. (2016). The role of institutional pressures in developing countries. Implications for IFRS. Theoretical and Applied Economics, 22 (2 (607), Summer), 27-40.

Samaha, K., \&Khlif, H. (2016). Adoption of and compliance with IFRS in developing countries: A synthesis of theories and directions for future research. Journal of Accounting in Emerging Economies, 6(1), 33-49.

Sedzani, F., And Minor D,. (2012).Challenges To The Adoption Of International Financial Reporting Standards In Africa, Master Thesis, University Of Johannesburg, south Africa.

Teferi, D., and Dr. J.S. Pasricha (Professor)., (2016).IFRS Adoption Progress In Ethiopia, Research Journal of Finance and Accounting, Vol.7, No.1. 